\title{
JEG-3 placental cells in toxicology studies: a promising tool to reveal pregnancy disorders
}

\author{
Elodie Olivier ${ }^{1}$, Anaïs Wakx ${ }^{1}$, Sophie Fouyet ${ }^{1}$, Mélody Dutot ${ }^{1,2}$, Patrice Rat ${ }^{1}$ \\ ${ }^{1}$ UMR CNRS 8038 CiTCoM, Laboratoire de Chimie-Toxicologie Analytique et Cellulaire, Université de Paris, Faculté de Pharmacie de Paris, Paris, \\ ${ }^{2}$ Recherche \& Développement, YSLAB, Quimper, France
}

\begin{abstract}
Placental alterations are responsible for adverse pregnancy outcomes like preeclampsia and intrauterine growth restriction. And yet, placenta toxicology has not become a fully-fledged toxicology field. Because placenta is very often seen only as a barrier between the mother and the fetus, there is a lack and therefore a need for an experimental human model with technical recommendations to study placenta toxicology. In vitro approaches are recommended in experimental toxicology as they focus on a specific biological process and yield high-throughput screening methods. In the present study, we first established incubation conditions to preserve signatures of the human JEG-3 cell line identity while enabling toxicity detection. JEG-3 cells prepared in our incubation conditions were renamed JEG-Tox cells. As placental alterations are mainly triggered by uncontrolled apoptosis, we second used known apoptotic agents pregnant women are exposed to, to check that JEG-Tox cells can trigger apoptosis. Ethanol, bisphenol F, quinalphos, 4,4'-DDT, benzalkonium chloride, phenoxyethanol, propylparaben, and perfluorooctanic acid all induced chromatin condensation in JEG-Tox cells. Our incubation conditions allow JEG-Tox cells to keep placental cell identity and to respond to toxic chemicals. JEG-Tox cells are a pertinent model for placenta toxicology and could be used to better understand pregnancy alterations.
\end{abstract}

Key words: Placenta, Toxicology, In vitro, Apoptosis, Hormones

Received September 2, 2020; Revised October 16, 2020; Accepted November 3, 2020

\section{Introduction}

Placenta supports the normal growth and development of the fetus by coordinating gas exchanges, metabolic transfer, immunological functions and by producing, metabolizing and regulating numerous hormones including polypeptide and steroid hormones $[1,2]$. Due to the key role of placenta during pregnancy, placental alterations are responsible for many adverse pregnancy outcomes like preeclampsia and intrauterine growth restriction [3-5]. The role of placenta goes

\section{Corresponding author:}

Elodie Olivier (i)

UMR CNRS 8038 CiTCoM, Laboratoire de Chimie-Toxicologie Analytique et Cellulaire, Université de Paris, Faculté de Pharmacie de Paris, 75006 Paris, France

E-mail: elodie.olivier@u-paris.fr beyond pregnancy since placental alterations can be risk factors for cognitive and visual development during childhood $[6,7]$. And yet, placenta is more studied as a barrier between mother and fetus in the scientific literature than a target organ for toxic agents (Fig. 1).

Its major role in pregnancy disorders should encourage scientists to consider placenta as a critical organ to further study its response to toxic agents. Hundreds of potential toxic chemicals used in daily life (food, cosmetics, drugs...) and environmental pollutants can be responsible for pregnancy disorders. Placental alterations then represent a growing concern worldwide and placenta toxicology is about to become a fully-fledged toxicology field like cardiotoxicology, hepatotoxicity, neurotoxicity... Placental apoptosis is increased in spontaneous abortion in the first trimester, preeclampsia, post-term pregnancies, and intra-uterine growth restriction $[8,9]$. Apoptosis is therefore a key endpoint in the assessment

\section{Copyright () 2021. Anatomy \& Cell Biology}

This is an Open Access article distributed under the terms of the Creative Commons Attribution Non-Commercial License (http://creativecommons.org/licenses/by-nc/4.0/) which permits unrestricted non-commercial use, distribution, and reproduction in any medium, provided the original work is properly cited. 


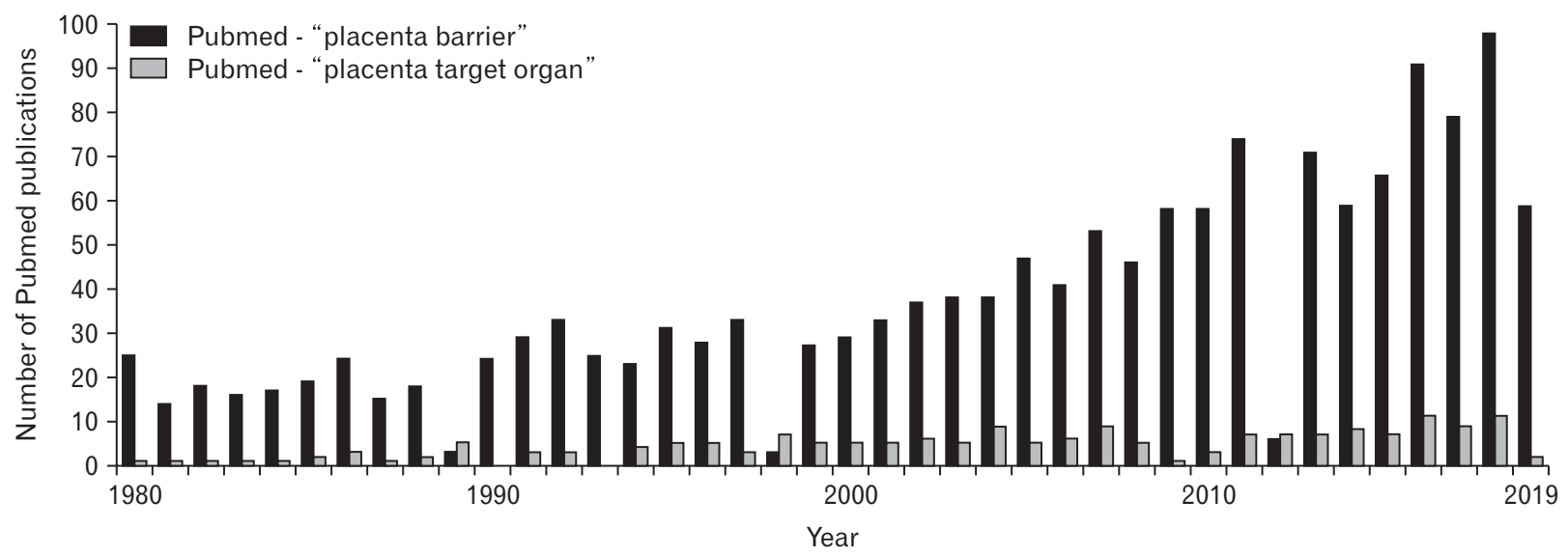

Fig. 1. Comparison of Pubmed publications using "placenta barrier" or "placenta target organ" as keywords in the research tool.

of potential risks for placental toxicity by chemicals.

Placental toxicity is in need of extensive investigation. Several models of placenta are available for toxicology studies. In vivo models are mainly mice, rats and rabbits, but placenta is the organ that shows the greatest diversity across mammalian species in its morphology and tissue organization, mechanisms of implantation and invasion, and endocrine regulation [10-12]. Animal models are consequently not fully suitable for the assessment of toxicological risk in the human placenta. Efforts are besides made to eliminate the use of animals in testing over the past 35 years in accordance to the 3R principle (Reduce, Refine, Replace). Perfused human placenta is the only model that respects the anatomical features of the human placenta [13], but the problem lies in the limited access to whole placenta for obvious technical and logistical reasons. Perfused human placentas as long as placenta-derived primary cultures are therefore not appropriate for high throughput screening. Moreover, it is almost impossible to control the maternal exposition to drugs, chemicals, cosmetics and pollutants that could influence the placental response to the toxic agent being studied. There are several different in vitro approaches currently available to evaluate chemicals toxicity in the human placenta. Immortalized cell lines can be bought in international cell banks like the American Type Culture Collection ATCC, the four main cell lines being HTR-8/SVneo, BeWo, JAR and JEG3 trophoblastic cells. Contrary to BeWo, JAR and JEG-3 cell lines, the HTR-8/SVneo is not derived from a choriocarcinoma and was immortalized by SV- 40 transfection. They show lower expression of proteins expressed by trophoblasts like cytokeratin-7 (CK7) and E-cadherin than BeWo, JEG-3 and JAR cell lines [14]. BeWo and JAR cells are less differ- entiated than JEG-3 cells. BeWo is best suited for studies on syncytial fusion as they are the only one to be fusigenic. JAR monolayers are unstable, as continued proliferation results in the formation of multilayers where ZO-1 and E-cadherin are lost from the cell surface [15]. With respect to TransEpithelial Electrical Resistance and electrical behaviour, JEG-3 are more similar to primary cells than BeWo and JAR cells [16]. For all these reasons, the human placental JEG-3 cell line is closer to human physiology than the other placenta cell lines and appears to be the best tool for the assessment of chemical toxicity in placenta. According to ATCC's instructions, JEG-3 cells are grown in MEM culture medium supplemented with $10 \%$ fetal bovine serum (FBS) to bring a large number of nutritional and macromolecular factors essential for cell growth and promote cell proliferation. Fetal serum may bind or adsorb chemicals and then mask their cytotoxicity [17, 18]. Low serum medium should be preferred in toxicological studies but how low is the question. We previously published numerous studies using different cell lines (tenocytes, corneal and retinal epithelial cells, macrophages and keratinocytes) that revealed the toxicity of chemicals in culture medium supplemented with serum reduced from $10 \%$ to $2.5 \%$ [19-22]. Based on our expertise, we suggest that the concentration of serum in JEG-3 cells should be reduced to $2.5 \%$ for toxicology studies.

The objective of the present paper is to establish incubation conditions for JEG-3 placental cells to reveal pregnancy disorders induced by chemicals. To achieve this objective, we first studied JEG-3 cells behavior in 2.5\% serum compared to $10 \%$, and second, we checked that JEG-3 cells are able to undergo apoptosis in response to chemicals toxic for pregnant women. 


\section{Materials and Methods}

\section{Materials}

All tested chemicals were purchased from Merck (Darmstadt, Germany) except ethanol (VWR Chemicals, Radnor, PA, USA) and perfluorooctanoic acid (PFOA; ThermoFisher Scientific, Waltham, MA, USA).

All cell culture reagents were obtained from Gibco (Paisley, UK). A 96-well microplates were purchased from Corning (Amsterdam, The Nederlands) and Nunc Lab-Tek II Chamber Slide system from Merck.

Antibodies were purchased from Merck (mouse anti-CK7 antibody) and ThermoFisher Scientific (Alexa Fluor 488 goat anti-mouse antibody and isotypic control). Fluorescent probes were obtained from ThermoFisher Scientific.

Fluorescence Resonance Energy Transfer (FRET) and ELISA kits were purchased from Cisbio Biosassays (Codolet, France) and MyBioSource (Vancouver, BC, Canada), respectively.

\section{Cell culture}

The choriocarcinoma-derived JEG-3 cell-line (ATCC HTB-36, Manassas, VA, USA), was grown as recommended by ATCC: Minimum Essential Medium Eagle's medium supplemented with $10 \%$ FBS, $2 \mathrm{mM}$ of glutamine, $50 \mathrm{IU} / \mathrm{ml}$ of penicillin and $50 \mathrm{IU} / \mathrm{ml}$ of streptomycin. Cells were detached using trypsin, counted, and then seeded at 80,000 cells $/ \mathrm{ml}$ in 96 -well microplates ( $200 \mu \mathrm{l}$ by well) and Nunc Lab-Tek II Chamber Slide system for immunostaining.

JEG-3 cells behavior in culture medium supplemented with different concentrations of serum

Impact of FBS concentration on cell proliferation

Cells were cultured in three different concentrations of FBS (using the same batch): $0 \%, 2.5 \%$ and $10 \%$. At 24 and 72 hours, cells were detached using trypsin and then counted by the Countess II Automated Cell Counter (ThermoFisher Scientific).

Cell line authentication by Short Tandem Repeat analysis (genetic profile)

Cell line DNA was profiled by Short Tandem Repeat (STR). This technique also checks the lack of cellular cross-contamination [23]. STR analysis was performed by the Human STR Profiling Cell Authentication Service of ATCC.

\section{CK7 immunostaining}

The CK7 intermediate filament is an established marker of trophoblastic cells [14, 24]. A 24 hours after seeding in culture medium supplemented with 2.5 or 10\% FBS, JEG-3 cells were fixed in $4 \%$ paraformaldehyde for 20 minutes, permeabilized in $0.1 \%$ Triton X-100 for 10 minutes, saturated with a solution of $1 \%$ BSA and $0.1 \%$ Tween in PBS for 2 hours, and then incubated overnight at $4^{\circ} \mathrm{C}$ with mouse anti-CK7 antibody $(196 \mu \mathrm{g} / \mathrm{ml})$ diluted in PBS containing $1 \%$ BSA and $0.1 \%$ Tween 20. After washing, the cells were incubated with Alexa Fluor 488 goat anti-mouse antibody $(4 \mu \mathrm{g} / \mathrm{ml})$ diluted in PBS containing 1\% BSA for 2 hours at room temperature. Nuclei were stained with $300 \mathrm{nM}$ DAPI for 5 minutes and Vectashield (Vector Laboratories, Burlingame, CA, USA) mounting medium was used for microscopy images (EVOS FL, ThermoFisher Scientific). Mouse IgG1 kappa clone P3.6.2.8.1 was used as an isotypic control to help differentiate nonspecific background signal from specific antibody signal.

\section{Hormone release quantitation}

After 72 hours of incubation in cell culture medium supplemented with $2.5 \%$ or $10 \%$ FBS, microplates were centrifuged, and cell supernatants were collected. Estradiol was quantified in cell supernatants by FRET technology (HTRF Cisbio Biosassays, Codolet, France) according to manufacturer's instructions. The detection limit of this assay is $20 \mathrm{pg} /$ $\mathrm{ml}$.

Human placental lactogen (hPl) hormone and human hyperglycosylated Chorionic Gonadotropin (hCG) hormone were measured by sandwich ELISA (MyBioSource) according to manufacturer's instructions. Sensitivities are $<46.875$ $\mathrm{pg} / \mathrm{ml}$ and $39 \mathrm{pg} / \mathrm{ml}$ for hPl and hCG dosage, respectively.

Impact of FBS concentration on sodium lauryl sulfate and PFOA cytotoxicity

Cells were incubated with sodium lauryl sulfate or PFOA diluted in culture medium supplemented with either $2.5 \%$ or $10 \%$ FBS. After 24 hours, cell viability was evaluated using the neutral red assay. Neutral Red solution at $0.4 \%$ in water was diluted in culture medium with a ratio of 1:79 to give a final concentration of $50 \mu \mathrm{g} / \mathrm{ml}$. Neutral Red was distributed in the plates for a 3 -hour incubation time at $37^{\circ} \mathrm{C}$. The cells were then rinsed with PBS to remove any remaining unincorporated dye. The dye was then released from the cells using a lysis solution (1\% acetic acid, 50\% ethanol and $\left.49 \% \mathrm{H}_{2} \mathrm{O}\right)$ and the fluorescence was measured $(\lambda \mathrm{ex}=540 \mathrm{~nm}$, 
Table 1. Tested toxic agents for apoptosis evaluation

\begin{tabular}{|c|c|c|c|}
\hline Chemical & $\begin{array}{l}\text { Source of } \\
\text { exposure }\end{array}$ & $\begin{array}{c}\text { Tested } \\
\text { concentrations }\end{array}$ & Solvent \\
\hline Ethanol & Beverage & $0.1 \%-10 \%(\mathrm{v} / \mathrm{v})$ & NA \\
\hline Quinalphos & $\begin{array}{l}\text { Environmental } \\
\text { pollution }\end{array}$ & $0.1-500 \mu \mathrm{M}$ & DMSO \\
\hline Bisphenol F & $\begin{array}{l}\text { Food and cosmetic } \\
\text { packaging }\end{array}$ & $0.1-200 \mu \mathrm{M}$ & DMSO \\
\hline 4,4'-DDT & $\begin{array}{l}\text { Food, environmental } \\
\text { pollution }\end{array}$ & $1-40 \mu \mathrm{M}$ & DMSO \\
\hline $\mathrm{BAC}$ & Health care products & $0.00001 \%-0.001 \%(\mathrm{~m} / \mathrm{v})$ & Water \\
\hline Phenoxyethanol & Cosmetics & $0.0001 \%-1 \%(\mathrm{v} / \mathrm{v})$ & NA \\
\hline Propylparaben & Cosmetics & $1-100 \mu \mathrm{M}$ & Ethanol \\
\hline PFOA & Food & $0.04-400 \mu \mathrm{g} / \mathrm{ml}$ & NA \\
\hline
\end{tabular}

4,4'DDT, 4,4'-dichlorodiphenyltrichloroethane; BAC, benzalkonium chloride; PFOA, perfluorooctanic acid; NA, not available.

$\lambda$ em=600 nm) using Spark microplate fluorometer (Tecan, Männedorf, Switzerland).

\section{Apoptosis evaluation after incubation with toxic agents}

\section{Toxic agents}

Tested toxic agents for apoptosis evaluation were detailed in Table 1. Solvents were evaluated alone to discriminate their potential effect (data not shown).

Determination of subcytotoxic concentrations

Known apoptotic agents were diluted in culture medium supplemented with 2.5\% FBS and incubated for 24 hours. Before running the apoptosis assay, cell viability was determined using the Alamar blue assay to eliminate necrotic concentrations and only keep subcytotoxic concentrations of the agents. Alamar blue was diluted in culture medium to a working concentration of $9 \mu \mathrm{g} / \mathrm{ml}$. The cells were incubated with the solution for 6 hours at $37^{\circ} \mathrm{C}$. The fluorescence signal was read $(\lambda \mathrm{ex}=535 \mathrm{~nm}, \lambda \mathrm{em}=600 \mathrm{~nm})$ using the Spark cytofluorometer.

Evaluation of chromatin condensation as a hallmark of apoptosis

The UV fluorescent probe Hoechst 33342 enters living and apoptotic cells, intercalating into DNA. The fluorescent signal is proportional to chromatin condensation in apoptosis. The cells were incubated with Hoechst 33342 at $10 \mu \mathrm{g} / \mathrm{ml}$ for 30 minutes at room temperature. The fluorescence signal was read $(\lambda \mathrm{ex}=360 \mathrm{~nm}, \lambda \mathrm{em}=460 \mathrm{~nm})$ using a cytofluorometer (Spark).

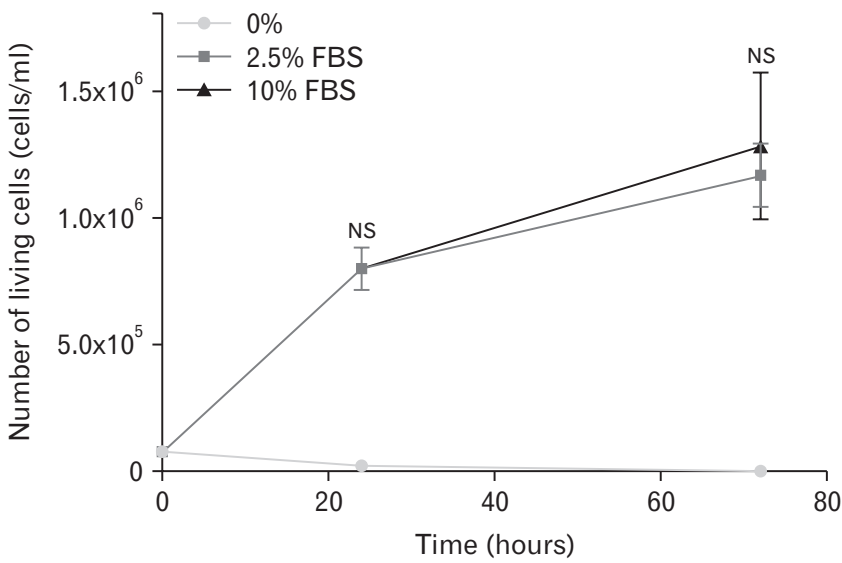

Fig. 2. Proliferation of JEG-3 cells in culture medium supplemented with different FBS concentrations. JEG-3 cells were incubated with three different concentrations of FBS for 24 or 72 hours, cell count was conducted to quantify the effect of FBS on JEG-3 cell proliferation. Black: 10\% FBS, grey: 2.5\% FBS, light grey: 0\% FBS. FBS, fetal bovine serum; NS, not significant.

\section{Statistical analysis}

Means of at least three independent experiments were calculated and normalized to control. A one-way ANOVA followed by Dunnett's test were performed ( $\alpha$ risk $=5 \%$ ) using GraphPad Prism 6 software (San Diego, CA, USA). Thresholds of significance were ${ }^{\star} P<0.05,{ }^{* *} P<0.01,{ }^{* *} P<0.001$, and ${ }^{* * * * P} P<0.0001$ compared to control.

\section{Results}

\section{JEG-3 cells behavior in culture medium supplemented with different concentrations of FBS}

Impact of FBS concentration on cell proliferation

Three percentages of FBS were used: $0 \%, 2.5 \%$, and 10\% in culture medium (Fig. 2).

The percentage of living cells was dramatically decreased after 24 hours in culture medium without FBS (0\% FBS); as expected, JEG-3 cells were not able to proliferate without FBS due to a lack of nutritional and macromolecular factors. JEG-3 cell proliferation in culture medium supplemented with $2.5 \%$ was similar to proliferation in $10 \%$ FBS at 24 and 72 hours.

\section{Cell line authentication by STR analysis}

The STR analysis was performed to compare nine STR core markers in JEG-3 cells in culture medium supplemented with $2.5 \%$ FBS to JEG-3 cells in 10\% FBS (Table 2). 
Table 2. STR analysis of JEG-3 cells cultured in culture medium supplemented with either $10 \%$ or $2.5 \%$ FBS

\begin{tabular}{|c|c|c|c|c|c|c|c|c|c|}
\hline \multirow{2}{*}{$\begin{array}{l}\text { Cell culture } \\
\text { condition }\end{array}$} & \multicolumn{9}{|c|}{ Loci } \\
\hline & D5S818 & D13S17 & D7S820 & D16S539 & vWA & THO1 & AMEL & TPOX & CSF1PO \\
\hline $10 \%$ FBS & 10,11 & 9,11 & 10,12 & 13,14 & 16 & $9,9.3$ & $\mathrm{X}, \mathrm{Y}$ & 8 & 11,12 \\
\hline $2.5 \%$ FBS & 10,11 & 9,11 & 10,12 & 13,14 & 16 & $9,9.3$ & $\mathrm{X}, \mathrm{Y}$ & 8 & 11,12 \\
\hline
\end{tabular}

STR, short tandem repeat; FBS, fetal bovine serum.

A

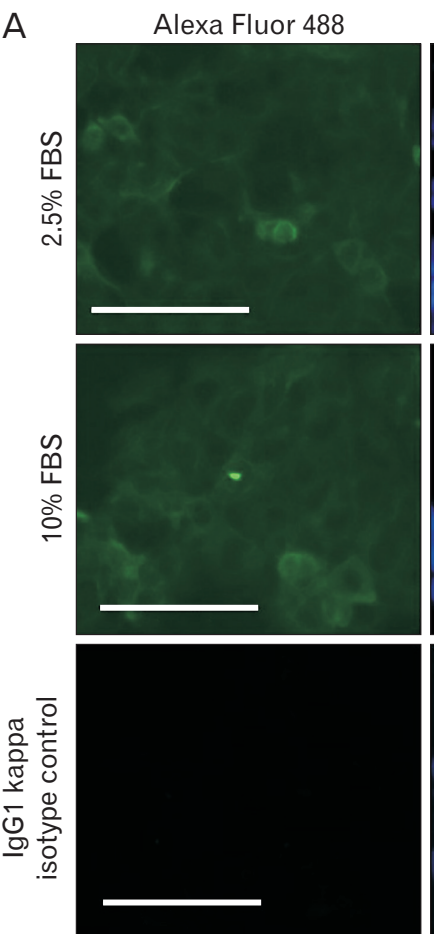

DAPI
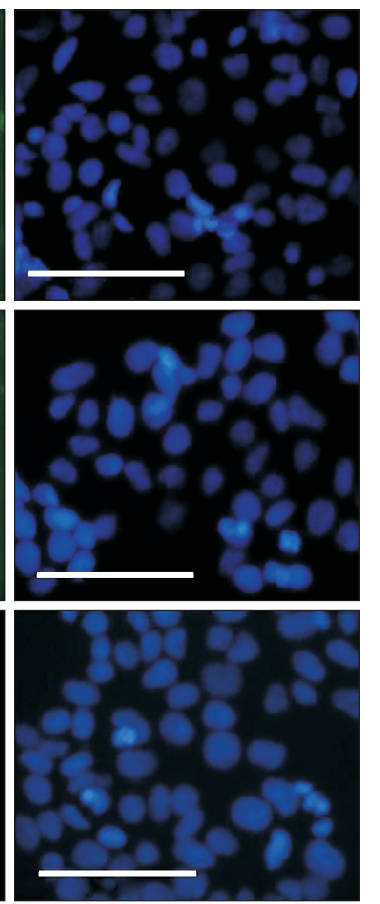

B

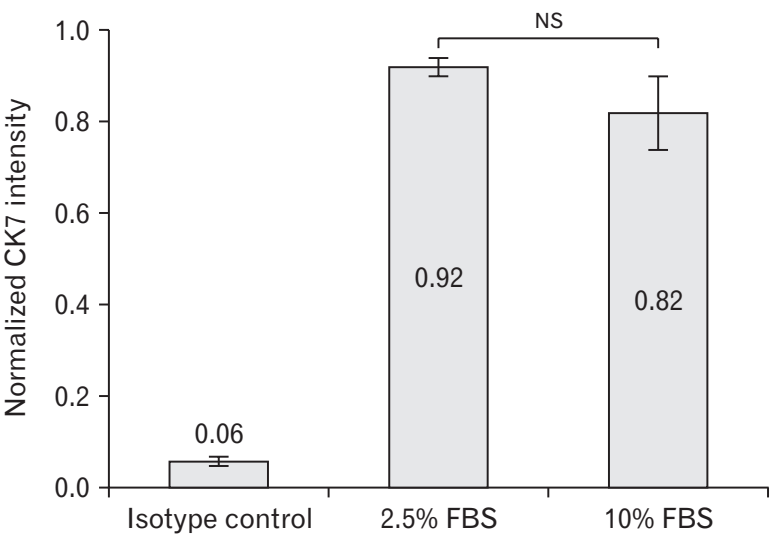

Fig. 3. Expression of CK7 in JEG-3 cells in 2.5\% and 10\% FBS. (A) Microscopic observation of JEG-3 cells stained with either anti-CK7 antibody or isotype control and then stained with Alexa Fluor 488 (green). DAPI was used to stain DNA (blue) (Magnification, $\times 200)$. Data are representative of at least 3 independent experiments. (B) Quantification of CK7 fluorescence using ImageJ software. Normalized CK7 fluorescence intensity was obtained by dividing green fluorescence intensity by blue fluorescence intensity to take into account the difference in cell numbers in the selected microscopic fields. CK7, cytokeratin-7; FBS, fetal bovine serum; NS, not significant. Scale bar=100 $\mu \mathrm{m}$ (A).

JEG-3 cells in $10 \%$ or $2.5 \%$ FBS expressed the same STR core markers. Reducing the percentage of FBS in culture medium of JEG-3 cells had no impact on DNA specific loci.

\section{Expression of CK7 as a marker of placental cells}

CK7 is a well-known epithelial marker for trophoblast cells and is known to be expressed in JEG-3 cells cultured in $10 \%$ FBS [14]. According to our microscopic observations, JEG-3 cells expressed similar levels of CK7 in 2.5\% FBS and $10 \%$ FBS (Fig. 3A). The expression of CK7 was quantified using ImageJ software (Fig. 3B) and no statistical differences were observed between 2.5\% FBS and 10\% FBS.

\section{Quantification of estradiol, hyperglycosylated $h C G$ and} hPL secretion by JEG-3 cells

We compared the secretion of placental hormones by JEG-3 cells in culture medium supplemented with $10 \%$ FBS to JEG-3 cells in 2.5\% FBS. After 24 hours in either medium, the levels of each hormone were comparable (Table 3).

\section{Impact of FBS concentration on sodium lauryl sulfate and PFOA cytotoxicity}

We compared sodium lauryl sulfate (SLS) and PFOA cytotoxicity in 2.5\% FBS and 10\% FBS, respectively (Fig. 4). At all tested concentrations, SLS diluted in culture medium supplemented with $10 \%$ FBS had no effect on JEG-3 cell viability. On the contrary, SLS diluted in culture medium supplemented with $2.5 \% \mathrm{FBS}$ induced cytotoxicity at $30 \mu \mathrm{g} /$ 
$\mathrm{ml}(37 \%$ of living cells, Fig. $4 \mathrm{~A})$ and $50 \mu \mathrm{g} / \mathrm{ml}$ (10\% of living cells). PFOA cytotoxicity was observed at $80 \mu \mathrm{g} / \mathrm{ml}$ and 120 $\mu \mathrm{g} / \mathrm{ml}$ in FBS $2.5 \%$ (68\% and $27 \%$ of living cells, respectively, Fig. 4B) whereas only a slight loss of cell viability was observed at $120 \mu \mathrm{g} / \mathrm{ml}$ in FBS $10 \%$ (85\% of viable cells). The classic concentration of FBS used for cell culture (10\% of total volume) tends to mask SLS and PFOA cytotoxicity contrary to reduced FBS concentration (2.5\%).

Based on our results, we pursue our study only using culture medium supplemented with FBS 2.5\%; we renamed cells with these incubation conditions JEG-Tox.

\section{Response of JEG-Tox cells to apoptosis inducers}

We studied chromatin condensation in JEG-Tox cells after incubation with apoptotic chemicals. Before assessing chromatin condensation, we selected subcytotoxic concentrations i.e. concentrations that result in $\%$ of living cells higher than 70 (data not shown). This threshold is recommended in ISO standards and OECD guidelines that assess cytotoxicity on monolayer cells. Subcytotoxic concentrations ranged from $0.1 \%$ to $5 \%$ for ethanol, from 0.03 to $150 \mu \mathrm{g} / \mathrm{ml}$ for quinal-

Table 3. Quantification of hormones in cell supernatants of JEG-3 cells in 10\% FBS or $2.5 \%$ FBS

\begin{tabular}{lccc}
\hline $\begin{array}{c}\text { Cell culture } \\
\text { condition }\end{array}$ & Estradiol $(\mathrm{ng} / \mathrm{ml})$ & hCG $(\mathrm{mUI} / \mathrm{ml})$ & $\mathrm{hPL}(\mu \mathrm{g} / \mathrm{ml})$ \\
\hline FBS 10\% & $1 \pm 0.2$ & $1.9 \pm 0.4$ & $2.1 \pm 0.6$ \\
FBS $2.5 \%$ & $1 \pm 0.6$ & $2.2 \pm 0.2$ & $1.5 \pm 0.3$ \\
$P$-value & $>0.9999(\mathrm{NS})$ & $0.7(\mathrm{NS})$ & $0.7(\mathrm{NS})$ \\
\hline
\end{tabular}

Values are presented as mean $\pm \mathrm{SD}$.

FBS, fetal bovine serum; hCG, human chorionic gonadotropin; hPL, human placental lactogen; NS, not significant.

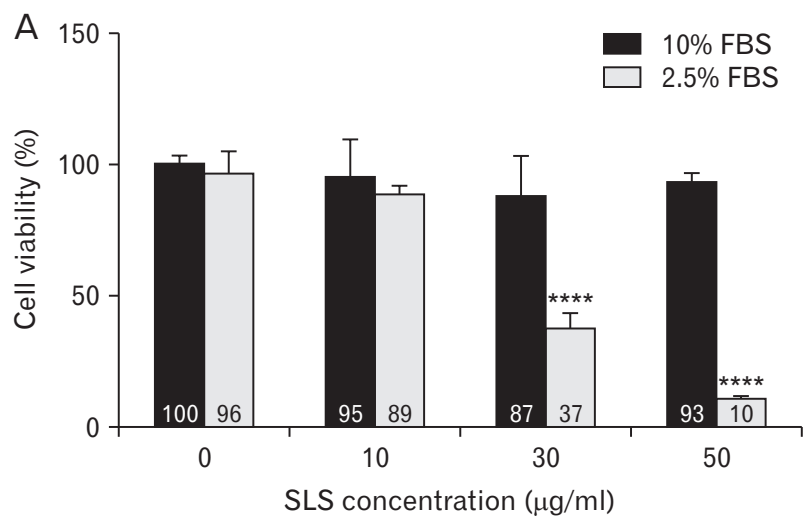

phos, from 2 to $20 \mu \mathrm{g} / \mathrm{ml}$ for bisphenol F, from 0.4 to $16 \mu \mathrm{g} /$ $\mathrm{ml}$ for 4,4 'DDT, from 0.1 to $2.5 \mu \mathrm{g} / \mathrm{ml}$ for BAC, from $0.0001 \%$ to $0.15 \%$ for phenoxyethanol, from 0.2 to $20 \mu \mathrm{g} / \mathrm{ml}$ for propylparaben and from 0.04 to $100 \mu \mathrm{g} / \mathrm{ml}$ for PFOA.

As shown in Fig. 5, all the apoptotic chemicals significantly induced chromatin condensation in JEG-Tox cells. Chromatin condensation was initiated with ethanol $2.5 \%$, quinalphos $0.3 \mu \mathrm{g} / \mathrm{ml}$, bisphenol F $5 \mu \mathrm{g} / \mathrm{ml}$, 4,4'DDT $2 \mu \mathrm{g} /$ $\mathrm{ml}$, BAC $2.5 \mu \mathrm{g} / \mathrm{ml}$, phenoxyethanol $0.15 \%$, propylparaben $20 \mu \mathrm{g} / \mathrm{ml}$ and PFOA $20 \mu \mathrm{g} / \mathrm{ml}$; all those concentrations being in accordance with the literature in other cell types [25-31].

\section{Discussion}

Chemicals are more concentrated in the placenta than in maternal tissues [32]. Exposure of pregnant women to hazardous chemicals and environmental pollutants like alcohol, pesticides, preservatives, or plasticizers can lead to decreased birth length and weight and increased infant mortality, alterations of developing nervous system and other vital organs, endocrine disruptions [33-36].

Proteins present in FBS can bind chemicals thus masking their potential cytotoxicity and affecting cell response. It was previously proposed that the protein corona formed around particles greatly influences particle toxicity [37]. High FBS concentrations used in growth medium (mainly 10\%) are therefore not suitable for toxicity studies. Some of our previous studies on ocular and skin cell lines demonstrated that $2.5 \%$ FBS is a good compromise as serum total deprivation induces cell death [38-40]. In this study, we compared placental JEG-3 cells behaviour in 2.5\% FBS versus 10\% FBS.

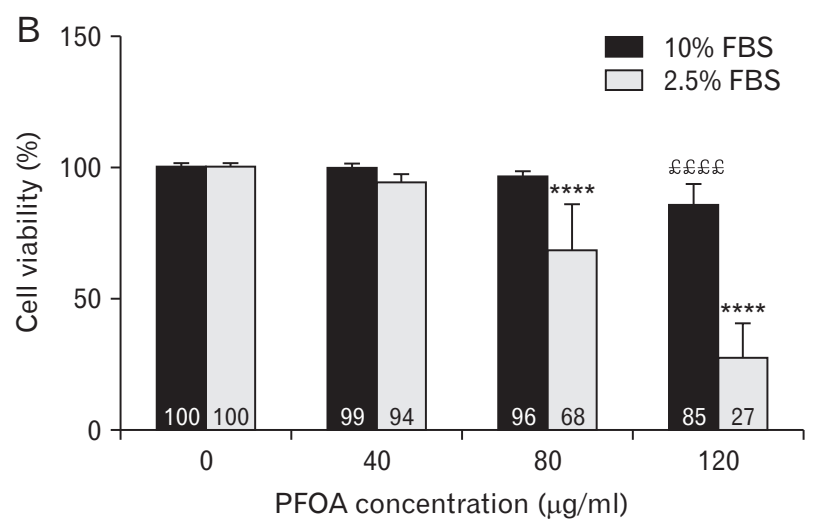

Fig. 4. Comparison of JEG-3 cell viability after incubation with SLS (A) or PFOA (B) in FBS 10\% or FBS 2.5\%. JEG-3 cells were incubated with SLS from 10 to $50 \mu \mathrm{g} / \mathrm{ml}$ or PFOA from 40 to $120 \mu \mathrm{M}$ for 24 hours. Cell viability was determined using the neutral red assay. ${ }^{£ \in \mathcal{E}} P<0.0001$ compared to negative control in $10 \%$ FBS, ${ }^{* * *} P<0.0001$ compared to negative control in $2.5 \%$ FBS $(\mathrm{n}=3)$. FBS, fetal bovine serum; PFOA, perfluorooctanic acid; SLS, sodium lauryl sulfate. 

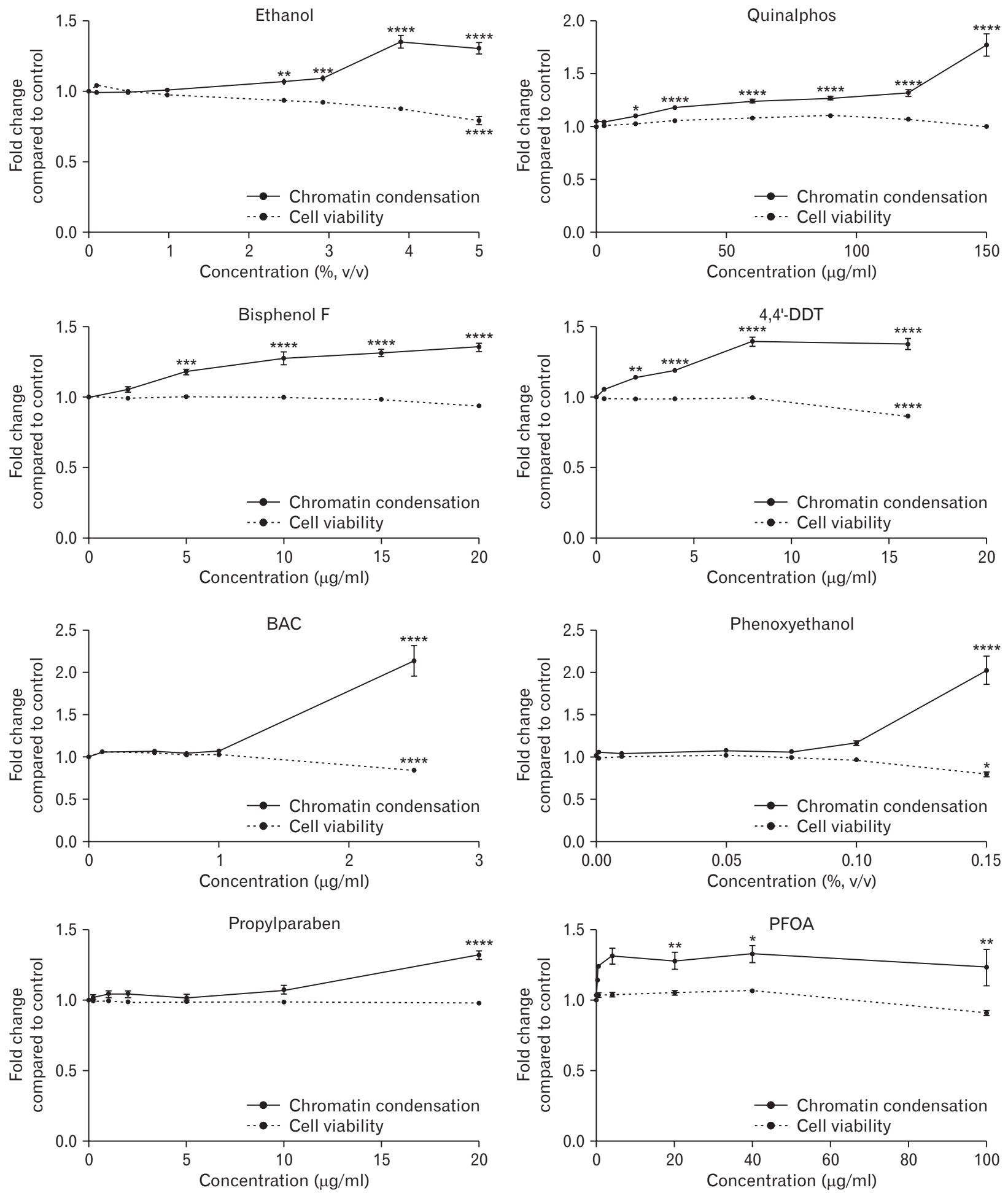

Fig. 5. Evaluation of cell viability and chromatin condensation of JEG-Tox cells after incubation with apoptosis inducers for 24 hours. Cell viability and chromatin condensation were quantified using the Alamar blue and Hoechst 33342 assays, respectively. Dashed line: cell viability, solid line: chromatin condensation. ${ }^{*} P<0.05,{ }^{* *} P<0.01$, ${ }^{* * *} P<0.001$, and ${ }^{* * * *} P<0.0001$ compared to negative control (n=3). BAC, benzalkonium chloride; PFOA, perfluorooctanic acid; 4,4’DDT, 4,4'-dichlorodiphenyltrichloroethane. 
We first evaluated cell proliferation and observed that JEG-3 cells cultured in $2.5 \%$ or $10 \%$ FBS have similar proliferation rates, and as expected, cells in $0 \%$ FBS did not survive. We second analysed STR core markers and concluded that JEG-3 cells had the same STR core markers and thus the same genotype whether they are cultured in $2.5 \%$ or in $10 \%$ FBS. We third performed immunochemistry studies to ensure that JEG-3 cells in 2.5\% FBS express CK7, a known marker of placental cells. Our results showed that reducing the percentage of FBS in JEG-3 cells does not alter signatures of cell identity such as cell proliferation rate, DNA profile and specific protein expression. JEG-3 cells in 2.5\% FBS released similar levels of hCG, hPL, and estradiol to JEG-3 cells in 10\% FBS, and thus maintain the endocrine function of human placenta.

In the cytotoxicity study, we didn't observe any cell death when SLS was diluted in $10 \%$ FBS up to $50 \mu \mathrm{g} / \mathrm{ml}$ whereas when it was diluted in $2.5 \%$ FBS, SLS induced a dramatic loss of cell viability at $30 \mu \mathrm{g} / \mathrm{ml}$. Cytotoxicity of PFOA was revealed at $200 \mu \mathrm{M}$ when it was diluted in $2.5 \%$ FBS whereas only a slight loss of cell viability was observed at $300 \mu \mathrm{M}$ when it was diluted in 10\% FBS. It appears that JEG-3 cells in $2.5 \%$ FBS are more suitable for toxicological studies than JEG-3 cells in 10\% FBS. We renamed JEG-3 cells in 2.5\% FBS JEG-Tox cells.

Apoptosis is suggested to be a key mechanism in placental dysfunction. A growing amount of data indeed suggests that uncontrolled placental apoptosis has side effects on both the placenta and maternal physiology [41]. To validate JEG-Tox cells as a pertinent model for the evaluation of placental toxicity, we checked whether they were able to trigger apoptosis after incubation with known apoptotic agents. We selected chemicals that pregnant women can be exposed to such as ethanol through alcohol consumption, preservatives present in cosmetics or drugs, pesticides and cookware coatings. In our experimental conditions, all the tested apoptotic chemicals induced chromatin condensation in JEG-Tox cells.

To conclude, reducing the percentage of FBS from $10 \%$, which is the recommended concentration for cell growth, to $2.5 \%$ does not affect neither DNA profile, nor placental marker, nor hormone secretion, but reveals placental toxicity increasing cell sensitivity to chemicals contrary to FBS $10 \%$. JEG-Tox cells can be of great value in placental toxicological studies, especially to study apoptosis that is at the origin of numerous severe pregnancy disorders.

\section{ORCID}

Elodie Olivier: https://orcid.org/0000-0002-6566-8170

Anaïs Wakx: https://orcid.org/0000-0003-2813-365X

Sophie Fouyet: https://orcid.org/0000-0002-1450-0458

Mélody Dutot: https://orcid.org/0000-0003-0964-0664

Patrice Rat: https://orcid.org/0000-0003-1270-4761

\section{Author Contributions}

Conceptualization: EO, MD, PR. Data acquisition: EO, AW, SF. Data analysis or interpretation: EO, MD. Drafting of the manuscript: EO, MD. Critical revision of the manuscript: PR. Approval of the final version of the manuscript: all authors.

\section{Conflicts of Interest}

No potential conflict of interest relevant to this article was reported.

\section{Acknowledgements}

We acknowledge support from Adebiopharm ER67 (Paris) and Troy Green for his linguistic support.

\section{References}

1. Griffiths SK, Campbell JP. Placental structure, function and drug transfer. Contin Educ Anaesth Crit Care Pain 2015;15:849.

2. Murphy VE, Smith R, Giles WB, Clifton VL. Endocrine regulation of human fetal growth: the role of the mother, placenta, and fetus. Endocr Rev 2006;27:141-69.

3. Chaddha V, Viero S, Huppertz B, Kingdom J. Developmental biology of the placenta and the origins of placental insufficiency. Semin Fetal Neonatal Med 2004;9:357-69.

4. Fisher SJ. The placental problem: linking abnormal cytotrophoblast differentiation to the maternal symptoms of preeclampsia. Reprod Biol Endocrinol 2004;2:53.

5. Ilekis JV, Tsilou E, Fisher S, Abrahams VM, Soares MJ, Cross JC, Zamudio S, Illsley NP, Myatt L, Colvis C, Costantine MM, Haas DM, Sadovsky Y, Weiner C, Rytting E, Bidwell G. Placental origins of adverse pregnancy outcomes: potential molecular targets: an Executive Workshop Summary of the Eunice Kennedy Shriver National Institute of Child Health and Human Development. Am J Obstet Gynecol 2016;215(1 Suppl):S1-46.

6. Innis SM. Fatty acids and early human development. Early Hum Dev 2007;83:761-6. 
7. Zhu Y, Mordaunt CE, Yasui DH, Marathe R, Coulson RL, Dunaway KW, Jianu JM, Walker CK, Ozonoff S, Hertz-Picciotto I, Schmidt RJ, LaSalle JM. Placental DNA methylation levels at CYP2E1 and IRS2 are associated with child outcome in a prospective autism study. Hum Mol Genet 2019;28:2659-74.

8. Smith SC, Baker PN, Symonds EM. Increased placental apoptosis in intrauterine growth restriction. Am J Obstet Gynecol 1997;177:1395-401.

9. Erel CT, Dane B, Calay Z, Kaleli S, Aydinli K. Apoptosis in the placenta of pregnancies complicated with IUGR. Int J Gynaecol Obstet 2001;73:229-35.

10. Enders AC, Blankenship TN. Comparative placental structure. Adv Drug Deliv Rev 1999;38:3-15.

11. Malassiné A, Frendo JL, Evain-Brion D. A comparison of placental development and endocrine functions between the human and mouse model. Hum Reprod Update 2003;9:531-9.

12. Schmidt A, Morales-Prieto DM, Pastuschek J, Fröhlich K, Markert UR. Only humans have human placentas: molecular differences between mice and humans. J Reprod Immunol 2015;108:65-71.

13. Ceccaldi PF, Mandelbrot L, Farinotti R, Forestier F, Gil S. [Contributions of the ex vivo human perfused placenta in the study of placental transfer of drugs]. J Gynecol Obstet Biol Reprod (Paris) 2010;39:601-5. French.

14. Abou-Kheir W, Barrak J, Hadadeh O, Daoud G. HTR-8/SVneo cell line contains a mixed population of cells. Placenta 2017;50:1-7.

15. Mitchell AM, Yap AS, Payne EJ, Manley SW, Mortimer RH. Characterization of cell polarity and epithelial junctions in the choriocarcinoma cell line, JAR. Placenta 1995;16:31-9.

16. Rothbauer M, Patel N, Gondola H, Siwetz M, Huppertz B, Ertl P. A comparative study of five physiological key parameters between four different human trophoblast-derived cell lines. Sci Rep 2017;7:5892.

17. Bohets HH, Nouwen EJ, De Broe ME, Dierickx PJ. Effects of foetal calf serum on cell viability, cytotoxicity and detoxification in the two kidney-derived cell lines LLC-PK1 and MDCK. Toxicol In Vitro 1994;8:559-61.

18. Lordan S, Higginbotham CL. Effect of serum concentration on the cytotoxicity of clay particles. Cell Biol Int 2012;36:57-61.

19. Pouzaud F, Dutot M, Martin C, Debray M, Warnet JM, Rat P. Age-dependent effects on redox status, oxidative stress, mitochondrial activity and toxicity induced by fluoroquinolones on primary cultures of rabbit tendon cells. Comp Biochem Physiol C Toxicol Pharmacol 2006;143:232-41.

20. Dutot M, Fagon R, Hemon M, Rat P. Antioxidant, anti-inflammatory, and anti-senescence activities of a phlorotannin-rich natural extract from brown seaweed Ascophyllum nodosum. Appl Biochem Biotechnol 2012;167:2234-40.

21. Wakx A, Dutot M, Massicot F, Mascarelli F, Limb GA, Rat P. Amyloid $\beta$ peptide induces apoptosis through P2X7 cell death receptor in retinal cells: modulation by marine omega-3 fatty acid DHA and EPA. Appl Biochem Biotechnol 2016;178:368-81.

22. Ghazi K, Deng-Pichon U, Warnet JM, Rat P. Hyaluronan frag- ments improve wound healing on in vitro cutaneous model through P2X7 purinoreceptor basal activation: role of molecular weight. PLoS One 2012;7:e48351.

23. Reid Y, Storts D, Riss T, Minor L. Authentication of human cell lines by STR DNA profiling analysis [Internet]. Bethesda, MD: Eli Lilly \& Company and the National Center for Advancing Translational Sciences; c2004 [cited 2019 Jul 19]. Available from: http://www.ncbi.nlm.nih.gov/books/NBK144066/.

24. Maldonado-Estrada J, Menu E, Roques P, Barré-Sinoussi F, Chaouat G. Evaluation of Cytokeratin 7 as an accurate intracellular marker with which to assess the purity of human placental villous trophoblast cells by flow cytometry. J Immunol Methods 2004;286:21-34.

25. Szuster-Ciesielska A, Plewka K, Daniluk J, Kandefer-Szerszeń M. Zinc inhibits ethanol-induced HepG2 cell apoptosis. Toxicol Appl Pharmacol 2008;229:1-9.

26. Zerin T, Song HY, Kim YS. Quinalphos induced intracellular ROS generation and apoptosis in human alveolar A549 cells. Mol Cell Toxicol 2015;11:61-9.

27. Mokra K, Kocia M, Michałowicz J. Bisphenol A and its analogs exhibit different apoptotic potential in peripheral blood mononuclear cells (in vitro study). Food Chem Toxicol 2015;84:79-88.

28. Carvalho CM, Menezes PF, Letenski GC, Praes CE, Feferman $\mathrm{IH}$, Lorencini M. In vitro induction of apoptosis, necrosis and genotoxicity by cosmetic preservatives: application of flow cytometry as a complementary analysis by NRU. Int J Cosmet Sci 2012;34:176-82.

29. Eggert A, Cisneros-Montalvo S, Anandan S, Musilli S, Stukenborg JB, Adamsson A, Nurmio M, Toppari J. The effects of perfluorooctanoic acid (PFOA) on fetal and adult rat testis. Reprod Toxicol 2019;90:68-76.

30. Jin X, Song L, Liu X, Chen M, Li Z, Cheng L, Ren H. Protective efficacy of vitamins $\mathrm{C}$ and $\mathrm{E}$ on p,p'-DDT-induced cytotoxicity via the ROS-mediated mitochondrial pathway and NF- $\mathrm{B} / \mathrm{FasL}$ pathway. PLoS One 2014;9:e113257.

31. Pozarowska D, Pozarowski P. Benzalkonium chloride (BAK) induces apoptosis or necrosis, but has no major influence on the cell cycle of Jurkat cells. Folia Histochem Cytobiol 2011;49:225-30.

32. Gupta RK, Gupta RC. Placental toxicity. In: Gupta RC, editor. Reproductive and Developmental Toxicology. 2nd ed. London: Academic Press; 2017. p.1301-25.

33. Nykjaer C, Alwan NA, Greenwood DC, Simpson NA, Hay AW, White KL, Cade JE. Maternal alcohol intake prior to and during pregnancy and risk of adverse birth outcomes: evidence from a British cohort. J Epidemiol Community Health 2014;68:542-9.

34. Ferguson KK, Rosen EM, Rosario Z, Feric Z, Calafat AM, McElrath TF, Vélez Vega C, Cordero JF, Alshawabkeh A, Meeker JD. Environmental phthalate exposure and preterm birth in the PROTECT birth cohort. Environ Int 2019;132:105099.

35. Ferguson KK, McElrath TF, Meeker JD. Environmental phthalate exposure and preterm birth. JAMA Pediatr 2014;168:61-7.

36. Barkoski JM, Busgang SA, Bixby M, Bennett D, Schmidt RJ, 
Barr DB, Panuwet P, Gennings C, Hertz-Picciotto I. Prenatal phenol and paraben exposures in relation to child neurodevelopment including autism spectrum disorders in the MARBLES study. Environ Res 2019;179(Pt A):108719.

37. Herzog E, Byrne HJ, Davoren M, Casey A, Duschl A, Oostingh GJ. Dispersion medium modulates oxidative stress response of human lung epithelial cells upon exposure to carbon nanomaterial samples. Toxicol Appl Pharmacol 2009;236:276-81.

38. Charles I, Khalyfa A, Kumar DM, Krishnamoorthy RR, Roque RS, Cooper N, Agarwal N. Serum deprivation induces apoptotic cell death of transformed rat retinal ganglion cells via mitochondrial signaling pathways. Invest Ophthalmol Vis Sci 2005;46:1330-8.

39. Koyama Y, Kimura Y, Yoshioka Y, Wakamatsu D, Kozaki R, Hashimoto H, Matsuda T, Baba A. Serum-deprivation induces cell death of rat cultured microglia accompanied with expression of Bax protein. Jpn J Pharmacol 2000;83:351-4.

40. Kulkarni GV, McCulloch CA. Serum deprivation induces apoptotic cell death in a subset of Balb/c 3T3 fibroblasts. J Cell Sci 1994;107(Pt 5):1169-79.

41. Sharp AN, Heazell AE, Crocker IP, Mor G. Placental apoptosis in health and disease. Am J Reprod Immunol 2010;64:159-69. 